\title{
Tumor-type-dependent effects on the angiogenic abilities of endothelial cells in an in vitro rat cell model
}

\author{
MAJIDA AL-ABBOODI ${ }^{1,2}$, RAN AN ${ }^{1,3}$, MAXIMILIAN WEBER $^{1}$, RAFAEL SCHMID ${ }^{1}$, ANNE KLAUSING ${ }^{1}$, \\ RAYMUND E. HORCH ${ }^{1}$, ANJA M. BOOS ${ }^{1,4}$ and ANNIKA KENGELBACH-WEIGAND ${ }^{1}$ \\ ${ }^{1}$ Department of Plastic and Hand Surgery, Laboratory for Tissue Engineering and Regenerative Medicine, \\ University Hospital of Erlangen, Friedrich-Alexander University Erlangen-Nürnberg (FAU), D-91054 Erlangen, \\ Germany; ${ }^{2}$ Institute of Genetic Engineering and Biotechnology, University of Baghdad, 10071 Baghdad, Iraq; \\ ${ }^{3}$ Department of Plastic Surgery, Union Hospital, Tongji Medical College, Huazhong University of Science and Technology, \\ Wuhan, Hubei 430022, P.R. China; ${ }^{4}$ Department of Plastic Surgery, Hand and Burn Surgery, \\ University Hospital RWTH Aachen, D-52074 Aachen, Germany
}

Received October 4, 2018; Accepted April 11, 2019

DOI: 10.3892/or.2019.7143

\begin{abstract}
Adequate vascularization is pivotal for tumor progression and metastasis. Tumor angiogenesis is based on a sequence of interactions between the tumor and surrounding cells and the extracellular matrix. It is widely known that a tumor can influence and control its surroundings to create favorable conditions for further growth. To investigate the influence of various tumor types on endothelial cells (ECs), an in vitro rat cell model was used and rat liver EC52 cells were co-cultured with conditioned medium derived from breast cancer MCR86, osteosarcoma ROS-1, colon cancer CC531 and rhabdomyosarcoma R1H cell lines. In a distinct tumor-type-dependent manner, the EC52 cells exhibited changes in their function and gene expression. In
\end{abstract}

Correspondence to: Dr Annika Kengelbach-Weigand, Department of Plastic and Hand Surgery, Laboratory for Tissue Engineering and Regenerative Medicine, University Hospital of Erlangen, Friedrich-Alexander University of Erlangen-Nürnberg, 12 Krankenhausstrasse, D-91054 Erlangen, Germany

E-mail: annika.kengelbach-weigand@uk-erlangen.de

Abbreviations: EC, endothelial cell; FCS, fetal calf serum; CM, conditioned medium; PECAM-1, platelet endothelial cell adhesion molecule-1; VEGF, vascular endothelial growth factor; FGF2, fibroblast growth factor 2; VWF, Von Willebrand factor; CXCL12, C-X-C motif chemokine ligand 12; TIE1, tyrosine kinase with immunoglobulin-like and EGF-like domains 1; PDGFRB, platelet-derived growth factor receptor $\beta$; EPC, endothelial progenitor cell; $\mathrm{MCP}-1$, monocyte chemoattractant protein-1; MIP-2, macrophage inflammatory protein 2- $\alpha$; TRAIL, TNF-related apoptosis-inducing ligand

Key words: tumor vascularization, endothelial cells, tumor microenvironment, colon cancer, breast cancer, osteosarcoma, rhabdomyosarcoma, pro-angiogenic factors all functional cell culture assays (proliferation, migration, transmigration, invasion and tube formation) the breast cancer cells exerted a significant effect on the angiogenic abilities of the ECs. When comparing the various tumor cell types, only the breast and colon cancer cells led to a significant stimulation of the EC migration and invasion. Proliferation, migration, invasion and tube formation were not or only hardly influenced by the osteosarcoma or rhabdomyosarcoma cells. Similarly, the breast and colon cancer cells exhibited the strongest influence on the upregulation of EC angiogenic genes, including the ones encoding vascular endothelial growth factor A, platelet and endothelial cell adhesion molecule 1, fibroblast growth factor 2, Von Willebrand factor, $\mathrm{C}-\mathrm{X}-\mathrm{C}$ motif chemokine ligand 12 and tyrosine kinase with immunoglobulin-like and EGF-like domains 1 . Therefore, it is hypothesized that tumor cells enhance the angiogenic properties of ECs, including proliferation, migration, invasion and tube formation in a tumor-type-dependent manner. This is likely based on the upregulation of pro-angiogenic genes in ECs induced by varying cytokine secretion signatures of tumor cells.

\section{Introduction}

Tumors develop as organ-like structures with a high metabolic demand (1). In the early stages, their growth depends on the passive diffusion of oxygen, nutrients and metabolic waste (2). When a tumor reaches 1-2 $\mathrm{mm}$ in diameter and its demand for oxygen and nutrients surpasses the local supply, hypoxia and nutrient starvation trigger an 'angiogenic switch' to allow for tumor progression (3). The further enlargement of these growths depends on angiogenesis initiated by cancerous cells to enhance the supply of oxygen and nutrients (4). Tumor angiogenesis involves a complex series of events, starting with vessel membrane degradation, followed by endothelial cell (EC) migration, proliferation and re-organization, promoting vessel maturation, indicating that ECs are essential in each step of angiogenesis (5). 
As ECs migrate towards a tumor, they can form loops and branches to connect with it and supply it with nutrients (6). This mechanism involves a complex interaction between many factors, including adhesion proteins, growth factors, junctional molecules, oxygen sensors and endogenous inhibitors (7). The crosstalk between tumor cells and ECs leads to modification of their properties and facilitation of the tumor cell function (8). It has been demonstrated that the tumor microenvironment contains a variety of cytokines regulating its angiogenesis (3). Pro- and anti-angiogenic molecules, necessary for blood vessel growth, are not only produced by tumor cells themselves, but can also be products of ECs, pericytes, the extracellular matrix and plasma clotting $(9,10)$. This complex interplay between stimulatory and inhibitory angiogenic factors is most likely influenced by the tumor cells in order to initiate and further support the vascular growth within the tumor (3). However, the underlying mechanisms and any tumor type variations remain unclear.

In the present study, the influence of various tumor types was analyzed, including that of breast cancer MCR86, osteosarcoma ROS-1, colon cancer CC531 and rhabdomyosarcoma R1H cells on EC52 cells in an in vitro rat cell model. Important steps occurring during tumor vascularization were examined, including EC proliferation, migration and tube formation, as well as subsequent underlying changes in genetic expression patterns. Investigation of tumor-induced angiogenesis may provide an improved understanding of tumor vascularization and progression, which in turn may lead to the development of novel anti-angiogenic therapeutic strategies in the future.

\section{Materials and methods}

Cell lines and cell culture. Rat colon adenocarcinoma CC531 cells (CLS Cell Lines Service GmbH, Eppelheim, Germany) were cultured in RPMI-1640 medium (Thermo Fisher Scientific Inc., Waltham, MA, USA) supplemented with $10 \%$ fetal calf serum (FCS; Biochrom Ltd., Cambridge, UK) and $2 \mathrm{mM}$ L-glutamine (Sigma-Aldrich; Merck KGaA, Darmstadt, Germany). Rat rhabdomyosarcoma R1H cells were obtained from Dr A. Raabe (Laboratory for Radiobiology and Experimental Radio-Oncology, University Cancer Center Hamburg, Hamburg, Germany) and were cultured in Dulbecco's modified Eagle's medium (Biochrom Ltd.) supplemented with 5\% FCS. Rat mammary carcinoma MCR86 cells were provided by Professor P. J. K. Kuppen (Department of Surgery, Leiden University Medical Center, Leiden, The Netherlands) and were cultured in RPMI-1640 medium supplemented with $10 \%$ FCS. Rat osteosarcoma ROS-1 cells were provided by Professor T. L. M. ten Hagen (Laboratory of Experimental Surgical Oncology, Department of Surgery, Erasmus MC, Rotterdam, The Netherlands) and were cultured in minimum essential medium (Sigma-Aldrich; Merck KGaA) supplemented with 10\% FCS. Rat liver EC52 cells were cultured in RPMI-1640 medium supplemented with 10\% FCS, $2 \mathrm{mM}$ L-glutamine and $1 \mu \mathrm{M}$ dexamethasone (PeloBiotech $\mathrm{GmbH}$, Planegg, Germany). All cell lines were incubated at $37^{\circ} \mathrm{C}$ in a humidified atmosphere of $95 \%$ air and $5 \% \mathrm{CO}_{2}$. The culture medium was changed every 2-3 days and the cells were passaged when $80-90 \%$ confluence was reached.
Direct co-culture of EC52 and tumor cells. A total of $2 \times 10^{4}$ tumor cells, including colon cancer CC531, rhabdomyosarcoma $\mathrm{R} 1 \mathrm{H}$, breast cancer MCR86 and osteosarcoma ROS-1 cells, were labeled with $25 \mu \mathrm{M}$ CellTrace ${ }^{\mathrm{TM}}$ Oregon Green ${ }^{\circledR} 488$ (Thermo Fisher Scientific Inc.), and 2×10 4 EC52 cells were labeled with $2 \mu \mathrm{M}$ PKH26 (Sigma-Aldrich; Merck KGaA), according to the manufacturers' protocols. Equal numbers of tumor cells and EC52 cells were mixed and seeded in 6-well plates. The co-cultured cells were incubated in a 1:1 mixture of tumor cell and EC52 cell culture media. Images were captured after 3-4 days using a fluorescent Olympus IX83 microscope and were analyzed with CellSens Dimensions 1.16 software (both from Olympus Corp., Tokyo, Japan).

Preparation of tumor-conditioned medium (CM). For tumor-CM, tumor cells were grown in their normal cell culture medium in cell culture flasks with an area of $75 \mathrm{~cm}^{2}$. When the cells reached $\sim 80 \%$ confluence, the medium was changed and the cells were cultured for another $48 \mathrm{~h}$. The supernatant was collected and filtered (pore size, $0.22 \mu \mathrm{m}$ ). The CM was mixed with fresh EC culture medium in a 1:1 ratio and used for the cell culture assays (termed tumor-CM). A 1:1 mixture of non-conditioned tumor cell and EC culture media was used as a negative control.

WST-8 cell proliferation and viability assay. To assess the effect of tumor-CM on EC52 proliferation, the quantitative colorimetric WST-8 assay (PromoCell GmbH, Heidelberg, Germany) was performed at 3 time-points. Briefly, EC52 cells were seeded at a density of $1 \times 10^{3}$ cells/well in $100 \mu \mathrm{lEC}$ culture medium in 96-well culture plates in triplicate. After $24 \mathrm{~h}$ of incubation, the medium was replaced with tumor-CM or control medium. After 24, 36 and $48 \mathrm{~h}$ of incubation, $10 \mu \mathrm{l}$ WST- 8 tetrazolium salt was added to each well for $2 \mathrm{~h}$ at $37^{\circ} \mathrm{C}$. For each measurement time-point one culture well plate was prepared. The absorption was measured at $450 \mathrm{~nm}$ with a reference wavelength of $600 \mathrm{~nm}$. After measurement, the culture well plate was discarded. The data was analyzed using SkanIt ${ }^{\mathrm{TM}}$ software version 3.2 (Thermo Fisher Scientific Inc.). The assay was performed 3 times.

Transwell migration and invasion assays. Transmigration and invasion assays were performed in a 24-well Transwell system (BD Biosciences, Franklin Lakes, NJ, USA) with $8-\mu \mathrm{m}$-pore polycarbonate membrane inserts. Transmigration was performed 2 times in technical duplicates. For statistical analyses the single technical duplicates were used. For the invasion experiments, the Transwell chambers were coated with $40 \mu \mathrm{l}$ growth factor reduced Matrigel ${ }^{\circledR}$ (Growth Factor Reduced Basement Membrane Matrix; Corning Inc., Corning, $\mathrm{NY}$, USA) and incubated for $60 \mathrm{~min}$ at $37^{\circ} \mathrm{C}$. Invasion was performed 3 times. A total of $1 \times 10^{5}$ EC52 cells/well were seeded into the upper chambers in $200 \mu \mathrm{l} \mathrm{EC}$ culture medium and $700 \mu \mathrm{l}$ tumor-CM or control medium was added to the bottom chambers. Following incubation at $37^{\circ} \mathrm{C}$ for $8 \mathrm{~h}$, the cells remaining on the surface of the membrane were wiped away using a cotton swab. The cells that migrated through the membrane were fixed with ice-cold methanol and stained with $1 \mu \mathrm{g} / \mathrm{ml}$ DAPI (Roche Molecular Diagnostics, Pleasanton, CA, USA). The stained cells were scanned and quantified 
in 4 random fields per membrane ( 1 image per quadrant) at an x40 magnification using an Olympus IX83 microscope. In a few wells only 3 regions of interest (ROIs) could be evaluated due to technical problems such as unclear images.

Wound-healing assay. A wound-healing assay was performed in 12-well plates. EC52 cells were seeded at a density of $1 \times 10^{5}$ cells/well in EC culture medium. When the cells reached confluence, a scratch was created using a $100-\mu 1$ pipette tip. The cell layer was washed with PBS and CM or control medium was added. Images were captured at 0, 6, 12 and $24 \mathrm{~h}$. The uncovered area of the scratch was measured in $\leq 4$ ROIs in each well and compared with the measurement at $0 \mathrm{~h}$, which was set to 1 . In certain wells, not all ROIs could be evaluated due to unequal cell growth at the borders of the well. The assay was performed 3 times.

Tube formation assay. Matrige ${ }^{\circledR}(10 \mu \mathrm{l})$ was applied to each well of a $\mu$-slide (a chambered coverslip) (ibidi GmbH, Martinsried, Germany) and incubated at $37^{\circ} \mathrm{C}$ for $30 \mathrm{~min}$ for gel polymerization. EC52 cells were seeded in technical triplicates at a density of $1.5 \times 10^{4}$ cells/well in $50 \mu 1$ tumor-CM or control medium on the surface of the gelled matrix. After $7 \mathrm{~h}$, the cells were stained with Calcein-AM (Sigma-Aldrich; Merck KGaA) and images were captured with an Olympus IX83 microscope and processed using CellSens software. Capillary-like tube formation was analyzed using the WimTube analysis software (Wimasis $\mathrm{GmbH}$, Munich, Germany) regarding covered area, tube length, branching points and loops. Tube formation was performed 3 times.

To detect the direct interaction of tumor cells and EC52 cells, 3.9 $\times 10^{3} \mathrm{CM}$ DiI dye-labeled tumor cells (staining solution $5 \mu \mathrm{g} / \mathrm{ml}$; Thermo Fisher Scientific Inc.) and $1.3 \times 10^{4}$ Oregon Green-labeled EC52 cells were seeded in direct co-cultures in Matrigel ${ }^{\circledR}$-coated wells, as described above, and incubated for $6 \mathrm{~h}$ in a 1:1 mixture of tumor-CM and EC52 cell culture medium. A monoculture of EC52 cells was grown as the control. The evaluation was performed as described above. Direct tube formation was performed once with technical triplicates that were used for statistical analysis.

Reverse transcription-quantitative polymerase chain reaction $(R T-q P C R)$. Total RNA was extracted from the EC52 cells incubated in tumor-CM for 4 days using the RNeasy Mini kit with the corresponding QIAshredder Homogenizer (both from Qiagen GmbH, Hilden, Germany). The RNA was converted to cDNA using the QuantiTect Reverse Transcription kit with a DNase I incubation $\left(15 \min 42^{\circ} \mathrm{C}, 3 \mathrm{~min} 95^{\circ} \mathrm{C}\right)($ Qiagen $\mathrm{GmbH})$. The qPCR reactions were performed using the SsoAdvanced Universal SYBR-Green SuperMix (Bio-Rad Laboratories, Inc., Hercules, CA, USA) with a Bio-Rad CFX96 Touch ${ }^{\mathrm{TM}}$ Light Cycler (Bio-Rad Laboratories, Inc.) and the following thermal cycling protocol: Polymerase activation and DNA denaturation: $30 \sec 95^{\circ} \mathrm{C}$, amplification: 40 cycles with denaturation at $95^{\circ} \mathrm{C}$ for $5 \mathrm{sec}$ and annealing at $60^{\circ} \mathrm{C}$ for $30 \mathrm{sec}$, melt-curve analysis $55-95^{\circ} \mathrm{C} 0.5^{\circ} \mathrm{C}$ increment $5 \mathrm{sec} / \mathrm{step}$. All kits were used according to the manufacturers' protocols and glucuronidase- $\beta$ was used as the housekeeping control. The primer sequences used are listed in Table I. All reactions were performed in triplicate. The experiment was performed
3 times. The expression of individual genes was calculated and normalized by the $2^{-\Delta \Delta \mathrm{Cq}}$ method (11).

Statistical analysis. The data are expressed as the mean \pm standard deviation. Statistical analysis was performed using SPSS version 20.0 software (IBM Corp., Armonk, NY, USA). Due to the small sample size with mostly $n=3$, non-parametric statistical tests were used since testing of normal distribution was considered to be negligible. In case of multiple comparisons, the Friedman test was used for dependent samples and the Kruskal-Wallis test was used for comparing independent samples. Mean differences between 2 independent samples were analyzed by the non-parametric Mann-Whitney U test; the asymptotic significance was used. Values of $\mathrm{P} \leq 0.05$ were considered to indicate statistically significant differences.

\section{Results}

Effects of tumor-CM on EC52 morphology and proliferation. EC52 cells in direct co-culture with various tumor cells grew in colonies with uniform and characteristic cobblestone appearance. No morphological changes were observed in the ECs. The co-cultured cells grew evenly with each other with no signs of overgrowth or inhibition of either one of the cell populations. Where direct cell-cell contact occurred, different interaction patterns were observed. In the rhabdomyosarcoma R1H co-culture, double-labeled cells were visible, indicating close cell-cell interactions. In many areas of the colon cancer CC531 co-culture, the ECs formed a border around the tumor cell colonies. In the culture with the breast cancer MCR86 cells, the tumor cells began to grow in close contact with the ECs and grew around EC colonies in certain areas (Fig. 1A).

The effect of tumor-CM on the viability and proliferation of EC52 cells was investigated using a WST-8 assay at 24,36 and $48 \mathrm{~h}$ of culture. The ECs proliferated over time in the tumor-CM as well as the control medium, mostly with a tendency of higher proliferation being observed in the tumor-CM (Fig. 1B-E). A significant increase in absorbance was observed when the ECs were cultured in R1H CM compared to control for $36 \mathrm{~h}(\mathrm{P} \leq 0.05)$ (Fig. 1C), as well as in

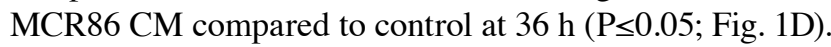

Tumor-CM promotes the migratory capacity of ECs. To investigate the effect of tumor-CM on the migratory ability of ECs, 3 distinct cell culture assays were performed. First, a wound-healing assay was conducted. Compared with that of the control, the migration of EC52 cells into the scratched area was increased in the CC531 and MCR86 CM. This difference became significant in the MCR86 CM compared to control at

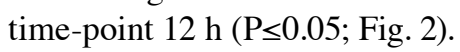

Subsequently, the influence of tumor- $\mathrm{CM}$ on the transmigration and invasion capacities of ECs was analyzed using Transwell assays. The transmigration was significantly stimulated in tumor-CM breast cancer MCR86 groups ( $\mathrm{P} \leq 0.05$; Fig. 3A and $\mathrm{B}$ ). The invasion of the ECs through the Matrigel ${ }^{\circledR}$-coated Boyden chambers was significantly stimulated by the colon cancer CC531 CM compared with the effect of the control ( $\mathrm{P} \leq 0.05$; Fig. $3 \mathrm{C})$. 
Table I. Primer sequences.

Forward Primer $\left(5^{\prime} \rightarrow 3^{\prime}\right)$

AGGGTCCTGGAGACTGATCC

Tie1

Flt1

Angpt2

Pecam 1

Cxcl12

Egf

Egfr

Vwf

Pdgfrb

Fgf2

Vegfa

Gusb
ACAGCAATGTGTTCCACAGCGT

AATGCACAGTAGCCCCTTCC

GCAGACCCTTCCACGAAGAA

TCCGTGGGCTCTGAGTTTTC

TCGAGTCAACAAAGGGCCTC

CAACATCCTGGAGGGGGAAC

CCCGGGAAACTCCTTCTTCC

GCATTGGCTCCATTCTTCAT

TCCATCAAGGGAGTGTGTGC

AATGATGAAGCCCTGGAGTG

TGGCCTTGGCTTTGTGTACT
Reverse Primer $\left(3^{\prime} \rightarrow 5^{\prime}\right)$

AAGGTACTGCATCCCGTTGG
TGGTTTCCTGCACCTGTTGCTT
GGTGCAGGCCTAAGTGATGT
GCTTCGGAGACTGGTCACAA
GGAACCCAGAATCCCCACTG
GAGTACCAGATCTGCCGCTC
ATGTTCATGGTCTGGGGCAG
CAAGCAAGTCACTGTGTGGC
CCGTGGTCATTCACACTCAC
GGACTCCAGGCGTTCAAAGA
ATGCTGCAGGAAGCTCATCT
CGTGGGTGCTAGGAATCGAA

AAGGTACTGCATCCCGTTGG

GGTGCAGGCCTAAGTGATGT

GCTTCGGAGACTGGTCACAA

GGAACCCAGAATCCCCACTG

GAGTACCAGATCTGCCGCTC

ATGTTCATGGTCTGGGGCAG

CAAGCAAGTCACTGTGTGGC

CCGTGGTCATTCACACTCAC

ATGCTGCAGGAAGCTCATCT

CGTGGGTGCTAGGAATCGAA
Stimulation of tube formation depends on direct cell-cell contact. To evaluate the angiogenic capabilities of ECs in a quantifiable manner, a tube-formation assay was performed. Following seeding on Matrigel ${ }^{\circledR}$, the EC52 cells formed typical endothelial networks in the tumor- $\mathrm{CM}$ and control medium with no significant differences (Fig. 4A-D).

To further analyze whether the stimulation of tube formation depends on direct cell-cell interactions, ECs and tumor cells were seeded in direct co-culture on Matrigel ${ }^{\circledR}$. By labeling tumor cells and ECs with different fluorescence dyes, the contribution of the different cell populations to tube formation could be visualized. The ECs directly co-cultured with breast cancer MCR86 cells displayed a significantly higher area, total tube length, number of branching points and total loops $(\mathrm{P} \leq 0.05)$ compared with the mono-cultured ECs (Fig. 4E-H). In addition, the total tube length was significantly longer in the rhabdomyosarcoma $\mathrm{R} 1 \mathrm{H}$ group compared with that of the control $(\mathrm{P} \leq 0.05$; Fig. $4 \mathrm{~F})$. Tumor cells were observed in close contact with the tubes formed by the ECs in all groups. Furthermore, the rhabdomyosarcoma R1H cells participated in forming tube-like structures by cell elongation and cell-cell interactions in close contact with the tubes formed by the ECs (Fig. 4I).

Tumor-CM upregulates angiogenesis-associated genes. Following incubation in tumor-CM for 4 days, the expression of 11 angiogenesis-associated genes in EC52 cells was determined by RT-qPCR (Fig. 5). In each group, the expression levels of angiogenic gene platelet endothelial cell adhesion molecule-1 (PECAMI) were significantly higher (except for ROS-1) in the tumor-CM compared with those in the control. The expression levels of other endothelial markers, including vascular endothelial growth factor A (VEGFA), fibroblast growth factor 2 ( $F G F 2$ ), Von Willebrand factor (VWF), C-X-C motif chemokine ligand 12 (CXCL12), tyrosine kinase with immunoglobulin-like and EGF-like domains 1 (TIE1), VEGF receptor 1 (VEGFR1) and platelet-derived growth factor receptor $\beta$ (PDGFRB) were significantly upregulated in groups stimulated with CC531 and MCR86 CM. PECAMI exhibited a 2-6-fold higher expression level in the colon cancer CC531 and breast cancer MCR86 groups compared with the rhabdomyosarcoma R1H and osteosarcoma ROS-1 groups. Whereas numerous angiogenesis-associated genes were upregulated in ECs that were cultured in the CC531 or MCR86 CM, only PECAM1 and CXCL12 in the R1H CM and VEGFA and TIE1 in the ROS-1 CM were significantly upregulated compared with the control.

\section{Discussion}

Angiogenesis is necessary for tumor growth, development and metastasis (8). Tumor vascularization is a complex multistep process. Important components of this process are EC proliferation and migration, followed by the formation of mostly abnormal capillaries $(12,13)$. ECs are stimulated by tumor-secreted factors to migrate and divide at the tumor sites, ultimately forming capillary structures stabilized by smooth muscle cells (14). Previous studies have demonstrated that. The tumor microenvironment serves a crucial role in its survival and development, and various factors influence its vascularization, however, the mechanism remains unclear $(3,15)$. As part of the tumor microenvironment, direct interaction of cancer cells with ECs may be of great importance for tumor metastasis, but also for tumor angiogenesis (16). Considering the growing awareness of the role of the tumor microenvironment in its progression, the present study aimed at deciphering its effect on tumor vascularization by studying the changes in phenotype and gene expression. Furthermore, the functional properties of ECs under the influence of various tumor types were analyzed. The design of the present tumor/EC in vitro model was based on previous studies (17-19).

In the direct co-culture, signs of cell-cell interactions between the tumor cells and ECs were observed. It is widely known that ECs in tumors have a unique activated phenotype compared with those under normal conditions (3). In the colon and breast cancer groups, the cells began to surround each other, perhaps due to tumor cell-secreted soluble factors, such as tumor necrosis factor $\alpha$, which can rearrange F-actin cytoskeleton filaments influencing the shape and motility of the cell (20), as well as transforming growth factor- $\beta$, which can 
A $\begin{gathered}\text { Oregon green } \\ \text { (tumor cells) }\end{gathered}$
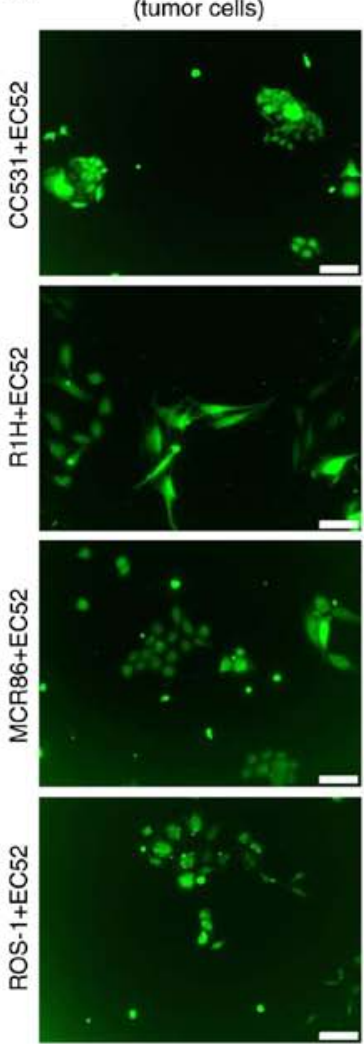

B

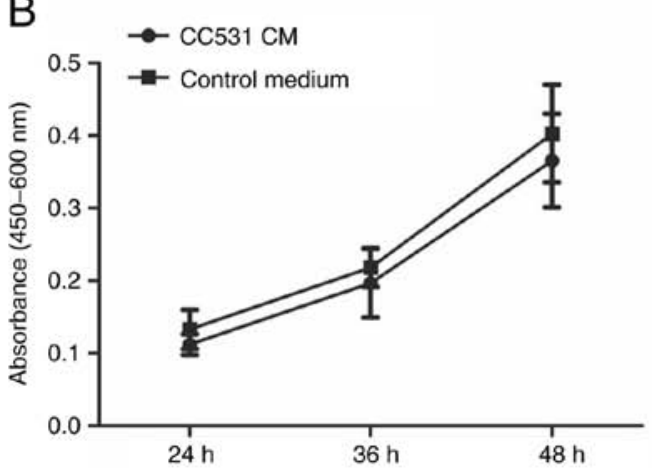

D

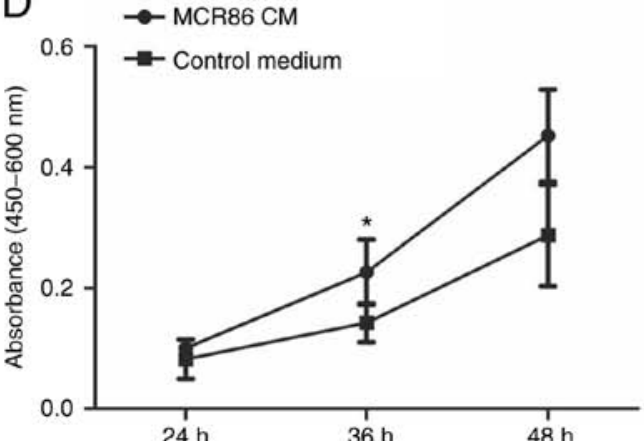

PKH26
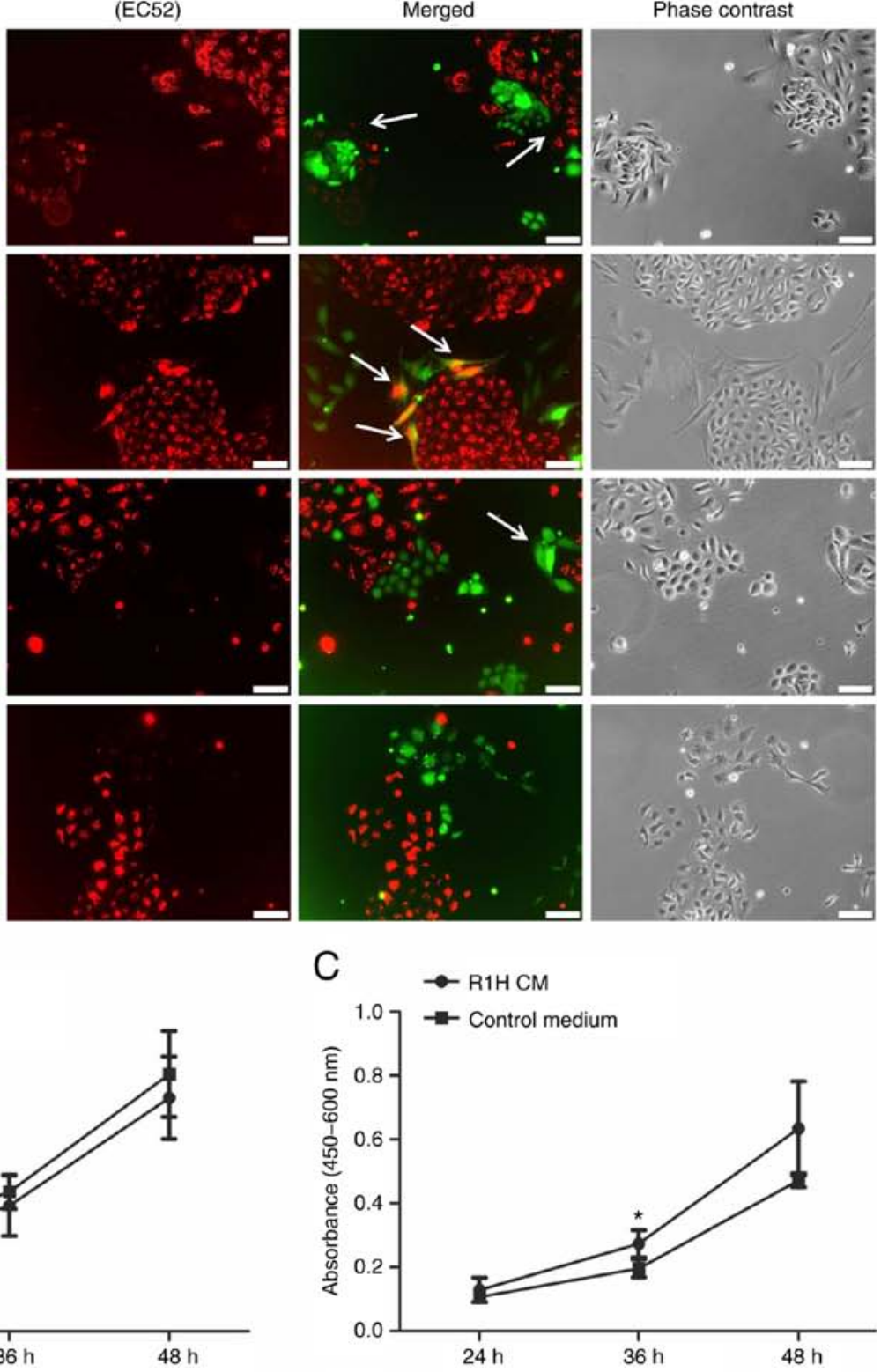

$\mathrm{E}$

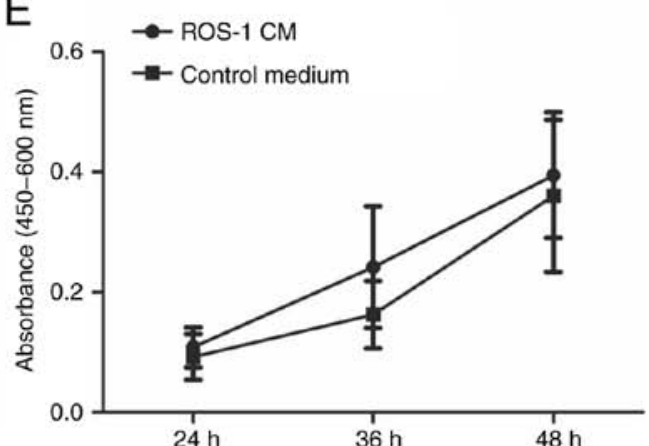

Figure 1. Morphology of EC52 cells in co-culture with tumor cells and their proliferation following culture in tumor-CM. (A) Representative images of EC52 cells co-cultured with tumor cells for 3-4 days. Oregon-Green-labeled tumor cells are indicated in green, and the PKH26-labeled EC52 cells are red. The arrows indicate direct cell-cell interactions and possible fusion can be observed. Scale bar, $100 \mu \mathrm{m}$. (B-E) Quantification of EC52 cell proliferation following incubation in tumor-CM and control medium for 24,36 and $48 \mathrm{~h}$. Results are expressed as the mean \pm standard deviation. "P $\leq 0.05$. CM, conditioned medium.

alter the content of collagen type IV and provide a supporting structure for ECs $(21,22)$. Although no distinct change in the morphology of the ECs could be detected, in certain areas they began to align with tumor cells in a manner similar to that reported by a study on the interaction between umbilical vein ECs and human glioma cells (22). Similar findings revealed that the CM derived from breast cancer cells affected the phenotype and behavior of normal cells (21). After a number 

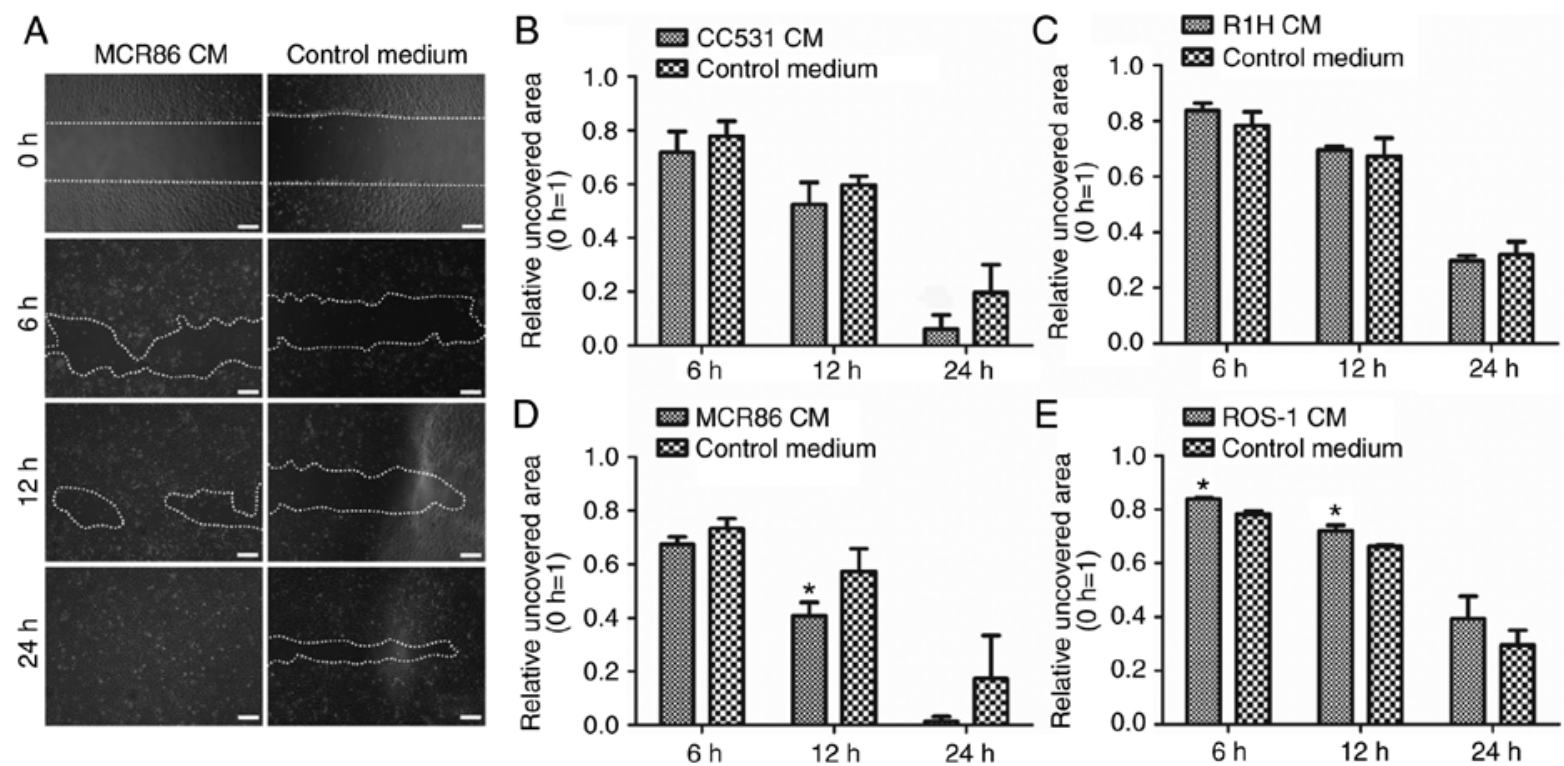

Figure 2. Effect of tumor-CM on the migration of EC52 cells. (A) Representative scratch test images of EC52 cell migration in breast cancer MCR86-CM and control medium. Scale bar, $200 \mu \mathrm{m}$. (B-E) Quantification of the covered area of EC52 cells induced by tumor-CM and control medium after 6, 12 and $24 \mathrm{~h}$. The bars represent the relative size of the uncovered area compared with that at time-point $0 \mathrm{~h}$ (data at $0 \mathrm{~h}$ is normalized to 1 ). The results are expressed as the mean \pm standard deviation. $\mathrm{P} \leq 0.05$. $\mathrm{CM}$, conditioned medium.

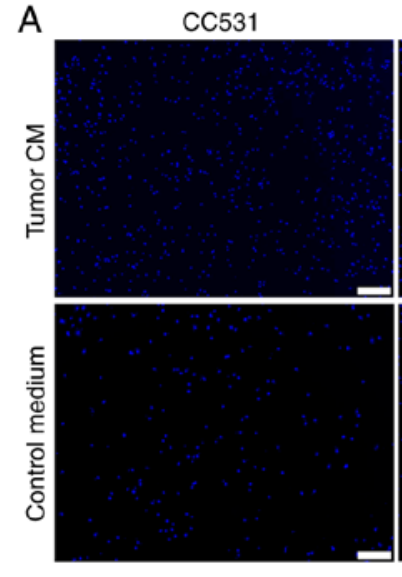

B
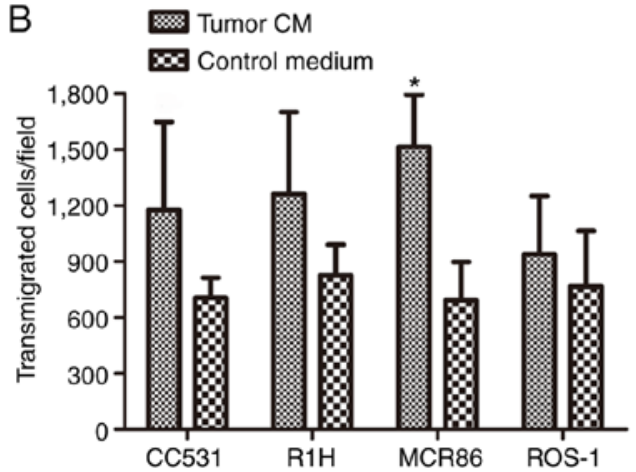

MCR86

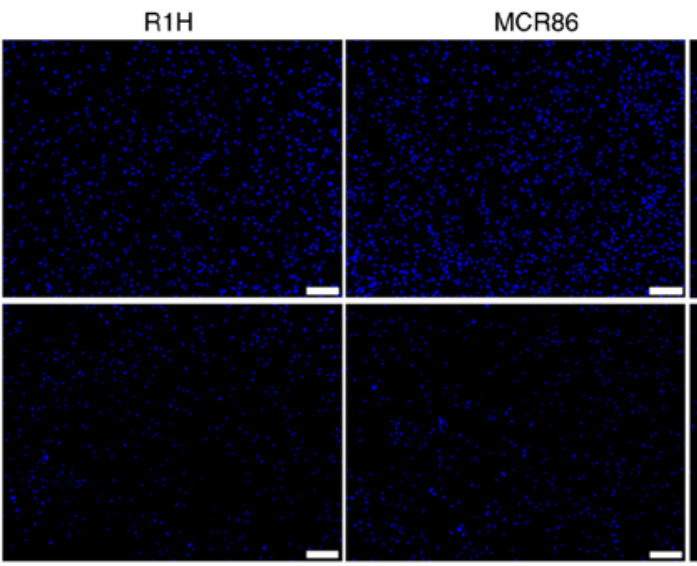

C
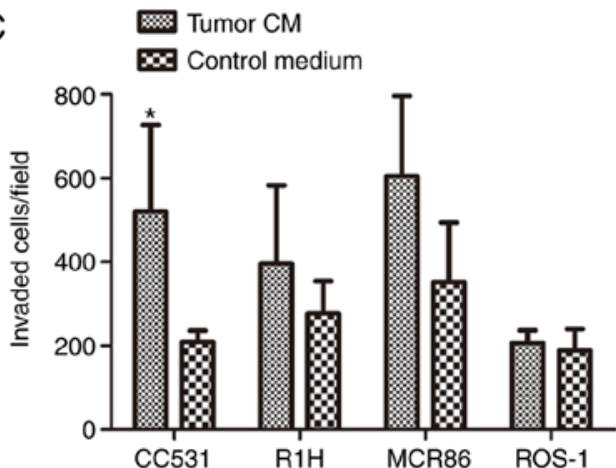

Figure 3. Effect of tumor-CM on invasion and transmigration of EC52 cells. (A) Representative images display the transmigration of EC52 cells stimulated by tumor-CM and control medium. Transmigrated EC52 cells are stained with DAPI (blue). Scale bar, $200 \mu \mathrm{m}$. (B and C) Quantification of the transmigration and invasion of EC52 cells following stimulation with tumor-CM and control medium. The results are expressed as the mean \pm standard deviation. ${ }^{*} \mathrm{P} \leq 0.05$. $\mathrm{CM}$, conditioned medium.

of days of co-culture, double-labeled cells became visible in the rhabdomyosarcoma group. This could be an indication of cell fusion, although loss of dye or it being absorbed up by other cells cannot be excluded. Tumor cells have the ability to fuse spontaneously with normal host cells, including ECs, which may alter the biological behavior of tumors (23). Cell fusion with macrophages or bone marrow-derived cells is quite a common feature of tumor cells to enhance metastasis, drug 

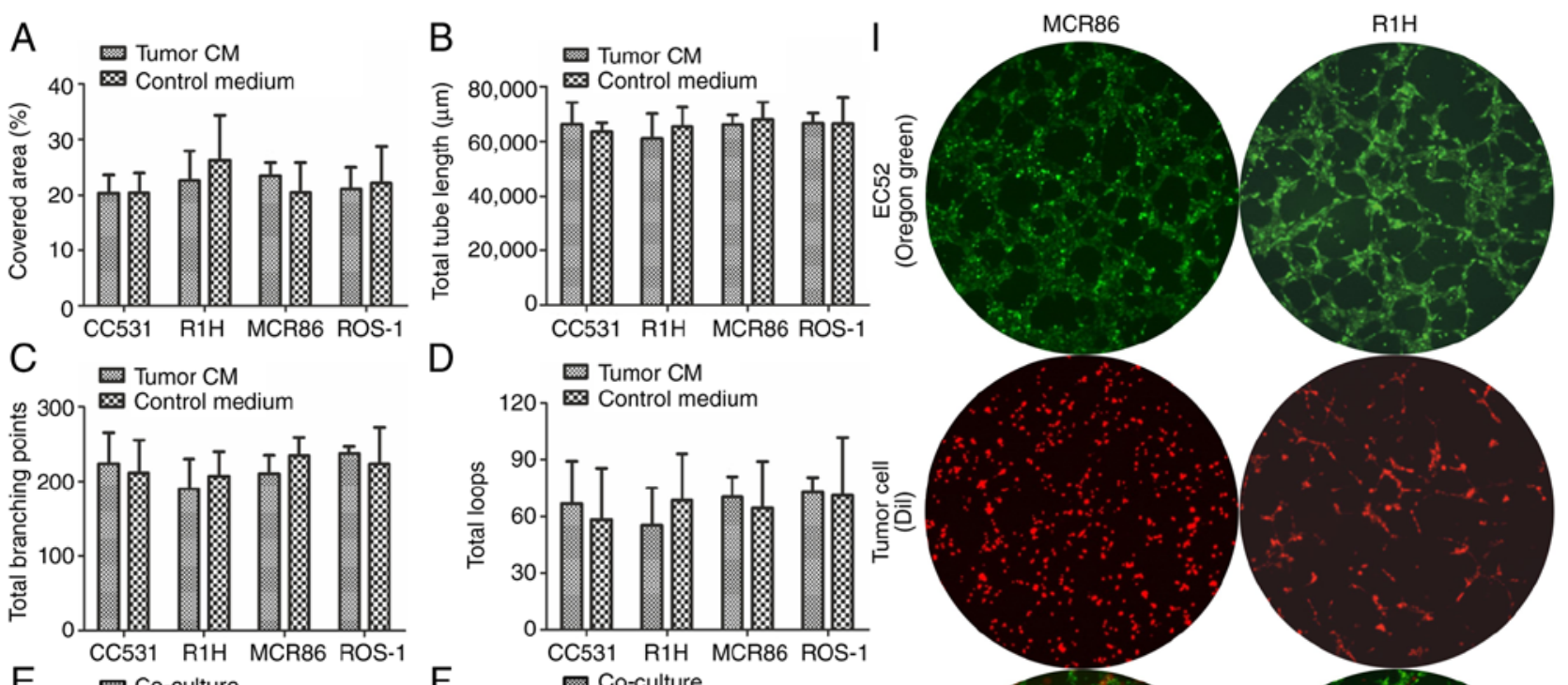

E $\quad$ Co-culture
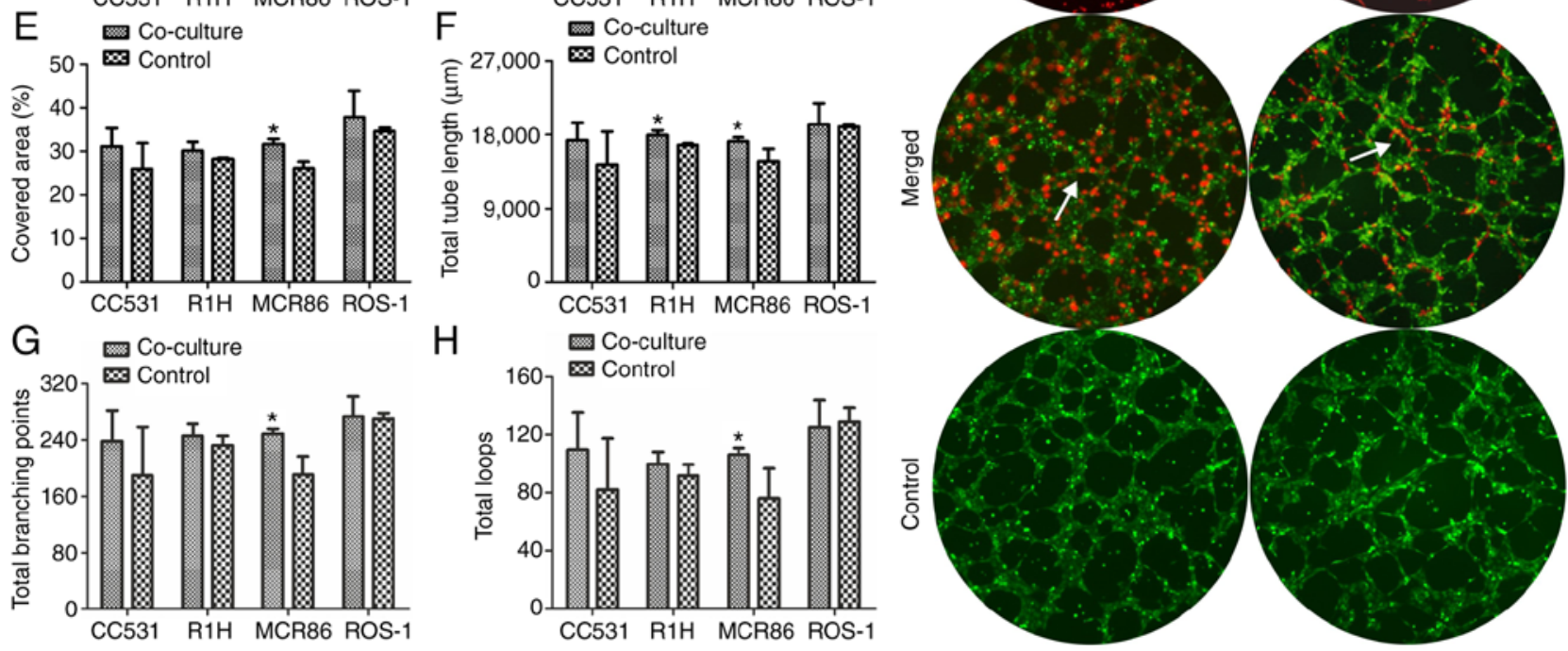

Figure 4. Tube formation of EC52 cells in tumor-CM and in direct co-culture with tumor cells. (A-D) Quantification of covered areas, total tube length, number of branching points, and total loops of tube formation generated by EC52 cells cultured in various tumor-CM and control medium. (E-H) Quantification of covered areas, total tube length, number of branching points, and total loops of tube formation generated by EC52 cells directly co-cultured with tumor cells. (I) Representative images of capillary-like tube structures generated by EC52 cells directly co-cultured with MCR86 and R1H tumor cells. DiI-labeled tumor cells are observed as red, and Oregon-green-labeled EC52 cells as green. The white arrows indicate the participation of tumor cells in tube formation. The results are expressed as the mean \pm standard deviation. ${ }^{*} \mathrm{P} \leq 0.05$. $\mathrm{CM}$, conditioned medium.

resistance and resistance to apoptosis (24). Similar findings were described in a study reporting on the direct co-culture of adipose-derived stem cells with breast cancer cells, indicating an exchange of cellular vesicles and fusion of cells, which led to a more malignant phenotype of the cancer cells (25). Hybrid cells derived from lung cancer cells and mesenchymal stem cells underwent an epithelial-mesenchymal transition (EMT), which resulted in a higher metastatic capacity and a higher expression of matrix metalloproteinase (MMP)2, MMP9 and typical mesenchymal markers, including vimentin (26). The authors suggest that this could be an explanation of the origin of lung cancer stem cells. A possible mechanism of the tumor-EC fusion was proposed by Mortensen et al (27), who demonstrated that, following intravascular dissemination, breast cancer cells fused with ECs in an in vivo mouse model. Hybrid cells exhibited markers of the two cell types and underwent mitosis. Although the present study did not further analyze cells in direct co-culture and drawing a distinct conclusion is therefore not possible, it was demonstrated that tumor cells not only interact with ECs in a paracrine way, but also via direct cell-cell contact.

The presence of actively proliferating and functional ECs is essential for tumor angiogenesis (16). To clarify if and to which extent the various tumor cell lines contribute to the proliferation of ECs, EC52 cells were incubated in the CM of tumor cell lines and their viability was analyzed by a WST- 8 assay. The breast cancer MCR86 and rhabdomyosarcoma R1H cells significantly stimulated the viability of the ECs. A previous study also detected a relatively low influence of tumor cells on the proliferation of endothelial progenitor cells (EPC), but a significant contribution to the recruitment and tube-like formation (28). Therefore, further experiments were performed focusing on the migration of ECs. As demonstrated by the WST-8 assay, the ECs were significantly affected by rhabdomyosarcoma and breast cancer cells. Their migration in the scratch test and the transmigration and invasion in the Boyden chamber assay were notably stimulated especially in the mammary 

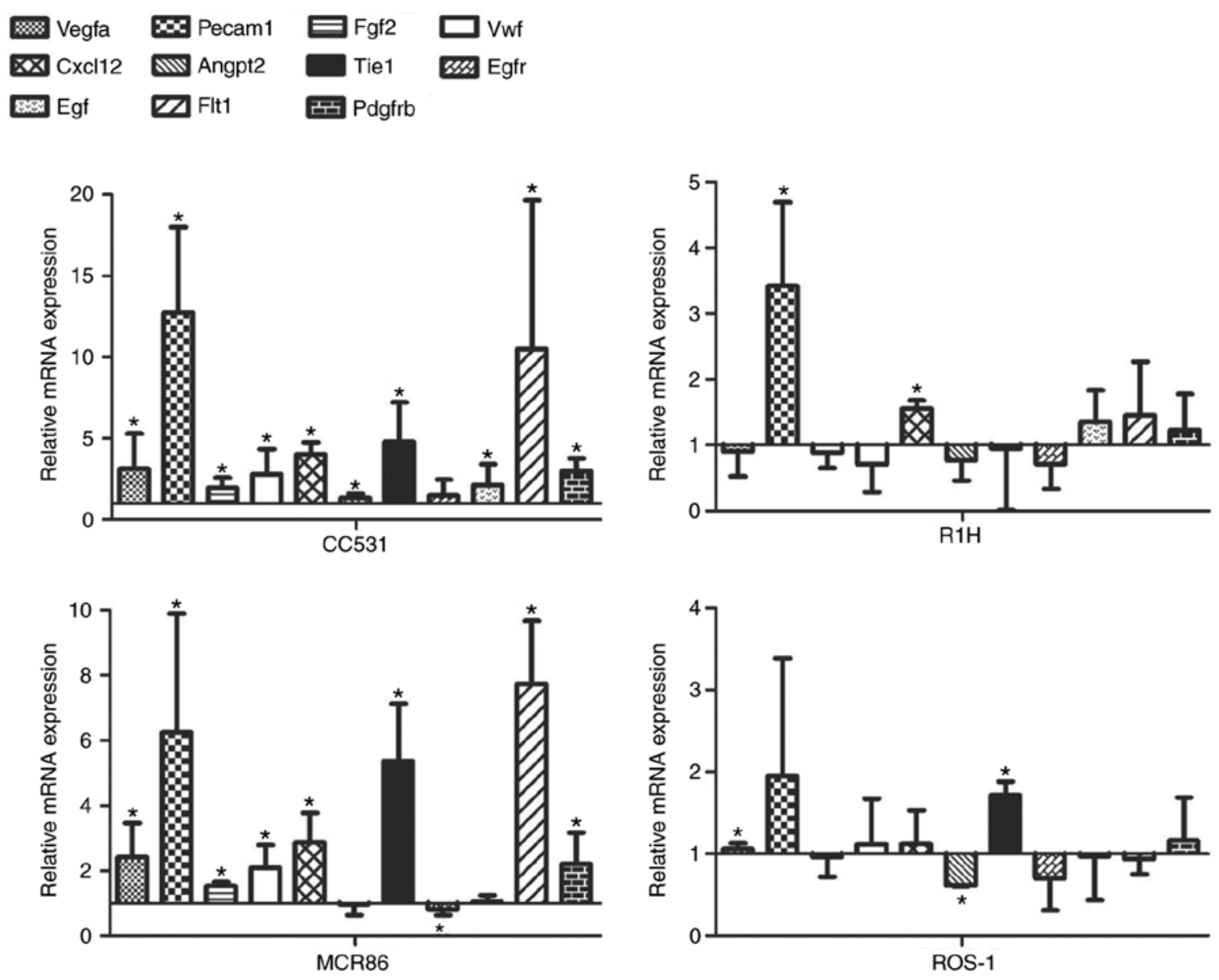

Figure 5. Effect of tumor-CM on gene expression in EC52 cells. Evaluation of the relative mRNA expression of 11 genes associated with angiogenesis and endothelial cell differentiation in EC52 cells following exposure to tumor-CM for 4 days compared with the control medium (the control data are normalized to 1). ${ }^{*} \mathrm{P} \leq 0.05$. CM, conditioned medium.

carcinoma CM. Ding et al (29) reported a positive correlation between increasing invasion and migration capacities and enhanced proliferation ability. This effect of the breast cancer cells appears not to be limited only to ECs, as they have also been demonstrated to activate an alteration in the morphology and migration properties of normal breast epithelial cells to trigger the EMT (21), and the chemotaxis of bone marrow-derived mesenchymal stromal cells (30).

The communication between ECs and other cell types is not only based on paracrine, but also on direct cell-cell interactions $(28,31)$. Therefore, a co-culture system with the incubation of ECs in tumor-CM was assessed in a tube-formation assay. Tube formation is an in vitro model for evaluating the differentiation of ECs into tube-like structures, occurring subsequent to proliferation and migration (32). As anticipated from the aforementioned findings, the breast cancer cell line significantly stimulated the ECs to form tubes in the direct co-culture system. Furthermore, the tumor cells participated in the formation of tube-like structures (Fig. 4E-I). These findings support the hypothesis that tumor cells can modify their properties to form tumor blood vessels in terms of vasculogenic mimicry $(28,33,34)$. However, the tumor-CM did not result in stimulating the EC52 cells to form capillary-like structures in the present study (Fig. 4A-D). This observation strengthens the hypothesis that tumor cells themselves contribute to tube formation rather than further stimulating the tube-formation capability of ECs.

Contrary to the present findings, the CM of hepatocellular carcinoma and esophageal squamous cell carcinoma cells enhanced the tube-formation abilities of ECs $(8,35)$. In another study, the CM from colon and breast cancer cells supported EC tube formation (36). On the one hand, these inconsistencies could be due to variances in cell lines, however they could also be explained by the different conditions of tumor-CM production. Possibly the concentration of tumor-derived pro-angiogenic factors in the $\mathrm{CM}$ produced in the present study is too low or the accumulation of metabolic waste products by tumor cells during the preparation of the $\mathrm{CM}$ is too high. On the other hand, since the effects of the tumor-CM in the other functional cell assays were notable, it is hypothesized that the tube formation in the present controls is itself high to the extent that a detectable increase is not possible.

Collectively, the present results demonstrated that breast cancer MCR86 cells exhibited the strongest potential to stimulate the angiogenic functions of ECs compared with the other assessed cancer types, supporting the clinical findings that invasive breast cancer belongs to the group of highly vascularized tumors and produces various angiogenic factors (37). The different effects observed among the tumor types can likely be linked to the soluble factors secreted by the tumor cells. In a previous study, the effect of these tumor cell lines on EPCs was 
analyzed and the results suggested that tumor-derived cytokines, such as monocyte chemoattractant protein-1 (MCP-1), macrophage inflammatory protein $2-\alpha$ (MIP-2) and TNF-related apoptosis-inducing ligand (TRAIL), may serve a vital role in the cell-cell communications of tumor cells with their neighbors (28).

Given the contribution of tumor cells in changing the functional properties of ECs, the question of implicated gene expression changes arose. Genes associated with the phenotype of tumor-activated ECs may include the expression of the tumor-specific/induced markers of neovascularization (22). ECs isolated from human tumors exhibit enhanced angiogenic capabilities, survival, adhesion to tumor cells, chemotaxis and motility by expressing distinct markers to modulate their functions $(3,38)$. PECAM1 was upregulated in each group. This gene serves a key role in the initiation of vasculogenesis and angiogenesis, involving EC interactions on a cell-cell basis, but also with extracellular matrix components (39). CXCL12 was significantly upregulated in the colon cancer CC531-, rhabdomyosarcoma R1H- and breast cancer MCR86-CM groups. This factor is typically expressed in stromal cells in various tissues and organs (40). However, it can interact synergistically with VEGF to promote the functions of vascular ECs, including cell migration, cell survival and changes in gene expression (41). TIE1 levels were highest in the breast cancer MCR86-CM. Upregulation of TIEI has been observed in a variety of human solid tumors and tumor ECs, and is associated with tumor progression (42). The increase in the angiogenic capabilities of ECs following culture in tumor-CM could be partly attributed to these genes, based on the consistent upregulation in all the assessed groups.

VEGFA, VWF, FGF2 and PDGFRB were revealed to be upregulated in the breast cancer MCR86- and colon cancer CC531-CM groups, and downregulated or unaffected in the osteosarcoma ROS-1- and rhabdomyosarcoma R1H-CM groups. The expression of VWF, an EC marker, is regulated by angiogenesis factors, such as FGF2 and VEGF. High $V W F$ mRNA levels in tumors may be an early sign of activation of the endothelium (43). PDGFR serves a key role in regulating the formation and function of blood vessels (44). These gene expression results reflect the findings of the present functional assays. In nearly all the angiogenesis assays a stimulating effect of the breast cancer MCR86 cells was observed on the ECs. Furthermore, colon cancer CC531- and breast cancer MCR86-CM significantly induced EC migration. Conversely, $\mathrm{CM}$ derived from rhabdomyosarcoma $\mathrm{R} 1 \mathrm{H}$ and osteosarcoma ROS-1, both categorized as sarcoma, induced nearly no significant changes in the functional assays or the expression of the majority of the tested genes, suggesting that the secretion of pro-angiogenic factors is likely dependent on the origin of the tumor cells.

Since it is widely reported that there is an association between vascularization density and disease prognosis for a number of carcinomas, but not sarcomas, this was evaluated by West et al (45) in 42 patients with high grade soft tissue sarcomas. The authors revealed no correlation between vascularization and metastasis or survival. In contrast, in invasive breast carcinoma, microvessel counts and density were associated with metastasis (46). Notably, Tomlinson et al (47) analyzed the angiogenesis patterns in sarcoma and carcinoma samples and demonstrated that, in breast carcinoma tumors, the vessels were clustered within the stroma, whereas the vessels in the sarcoma stroma were homogeneously distributed. This could be due to the fibroblasts and myoblasts within the carcinoma stroma leading to a compartmentalization of the tumor, and thus of the angiogenic factors (47). In a review by Rocchi et al (48), the authors concluded that the angiogenesis in sarcomas could also serve an important role, but that there is an urgent requirement to analyze sarcoma neovascularization in greater detail. Based on the findings of the present study it can be concluded that the effect of carcinoma cells on angiogenesis is stronger than that of sarcoma cells. Whether this is associated with enhanced tumor progression or disease prognosis is to be evaluated in further in vivo studies. In the present study, rat tumor cell lines originating from tumors grown in the WAG/Rij rat were used. This allows using the same tumor cell lines in an established in vivo rat model for future studies making the translation from in vitro to in vivo much simpler. Further, using the WAG/Rij rat we can be certain that tumor cell lines used in the present study will grow in vivo. This would only be possible with human tumor cell lines when using an immunodeficient rat model with the disadvantage of having no immune system which is described to have an important effect for tumor growth and development.

Collectively, these results demonstrated that tumor-CM exerts a significant influence on the gene expression in ECs, leading to a modulation of signaling pathways that mediate the EC response. Significant upregulation of pro-angiogenic genes in ECs following culture in various tumor-CM is in agreement with the findings of enhanced angiogenic capacities of ECs in certain groups. The activation of quiescent ECs, which in turn secret pro-angiogenic factors such as VEGF and FGF, can further lead to an autocrine and paracrine loop of angiogenesis stimulation (1). Therefore, it is reasonable to assume that tumor-CM exerts an effect on tumor angiogenesis by inducing the expression of pro-angiogenic genes in ECs. Previous findings demonstrated that CM derived from these various tumor cell types contain diverse secreted growth factors in varying amounts, capable of affecting the functional behavior of mature, but also of EPCs to different extents (28). Future studies should focus on which distinct factors, most likely among MCP-1, MIP-2, and TRAIL, serve a significant role in the interaction of tumor cells and mature ECs. Based on the present findings, the development of antibodies against these tumor cell-secreted molecules could provide a novel therapeutic option for treatment of highly vascularized tumors. Recently, a study by Kami Reddy et al (49) proposed the use of a novel inhibitor against dimethylarginine dimethylaminohydrolase 1 (DDAH1) for the treatment of prostate cancer. Inhibition of DDAH1 abrogated the secretion of angiogenic growth factors and reduced the vascularization of tumors, which led to an inhibition of xenograft tumors (49). Another approach to block the tumor-EC interaction is the inhibition of VEGFR1, which serves a role in tumor-associated, but not in adult physiological angiogenesis (50). Selective inhibition of this receptor would open up a new perspective in the treatment of highly vascularized tumors.

In summary, the present study demonstrated that tumor cells can significantly enhance the pro-angiogenic properties of ECs, including proliferation, migration, invasion and tube 
formation, in a tumor-type-dependent manner, by influencing the genetic expression in ECs. Comparing the 4 distinct tumor types analyzed within this study, the breast cancer MCR86 cell line exhibited the greatest influence on the behavior of ECs. It is now the aim of future studies to evaluate the effectiveness of inhibiting tumor cell-secreted molecules to block the tumor-EC interaction in highly vascularized tumors.

\section{Acknowledgements}

The authors would like to thank Dr A. Raabe (University Cancer Center Hamburg, Hamburg, Germany) for providing the R1H cells; Professor P.J.K. Kuppen (Leiden University Medical Center, Leiden, The Netherlands) for providing the MCR86 cells; Professor T.L.M. ten Hagen (Erasmus Medical Center, Rotterdam, The Netherlands) for providing the ROS-1 cells; and Mr. S. Fleischer and Mrs. I. Arnold-Herberth (University Hospital of Erlangen, Erlangen, Germany) for their excellent technical support.

\section{Funding}

The present study was funded by the Staedtler Foundation, ELAN-Fonds (grant no. 13-03-18-1-Brandl/Boos), University of Erlangen-Nürnberg, The Interdisciplinary Center for Clinical Research (IZKF, Faculty of Medicine, Friedrich-Alexander University of Erlangen-Nürnberg), the Medicine Research Foundation, University of Erlangen-Nürnberg and the Xue Hong and Hans Georg Geis Foundation.

\section{Availability of data and materials}

The datasets used and/or analyzed during the present study are available from the corresponding author on reasonable request.

\section{Authors' contributions}

MAA, RA, AMB, REH and AKW designed the study research and participated in the manuscript preparation, revision and data analysis. RS performed the quantitative polymerase chain reaction assays and data analysis. MW and MAA performed the proliferation and tube formation assays and the data analysis. AK assisted with the migration, transmigration and invasion assays and data analysis. All authors read and approved the manuscript and agree to be accountable for all aspects of the research in ensuring that the accuracy or integrity of any part of the work are appropriately investigated and resolved.

\section{Ethics approval and consent to participate}

Not applicable.

\section{Patient consent for publication}

Not applicable.

\section{Competing interests}

The authors declare that they have no competing interests.

\section{References}

1. Ronca R, Van Ginderachter JA and Turtoi A: Paracrine interactions of cancer-associated fibroblasts, macrophages and endothelial cells: Tumor allies and foes. Curr Opin Oncol 30: 45-53, 2018.

2. Carmeliet P and Jain RK: Angiogenesis in cancer and other diseases. Nature 407: 249-257, 2000.

3. Weis SM and Cheresh DA: Tumor angiogenesis: Molecular pathways and therapeutic targets. Nat Med 17: 1359-1370, 2011.

4. Billy F, Ribba B, Saut O, Morre-Trouilhet H, Colin T, Bresch D, Boissel JP, Grenier E and Flandrois JP: A pharmacologically based multiscale mathematical model of angiogenesis and its use in investigating the efficacy of a new cancer treatment strategy. J Theor Biol 260: 545-562, 2009.

5. Bai Y, Bai L, Zhou J, Chen H and Zhang L: Sequential delivery of VEGF, FGF-2 and PDGF from the polymeric system enhance HUVECs angiogenesis in vitro and CAM angiogenesis. Cell Immunol 323: 19-32, 2017.

6. Hosseini F and Naghavi N: Modelling tumor-induced angiogenesis: combination of stochastic sprout spacing and sprout progression. J Biomed Phys Eng 7: 233-256, 2017.

7. Laschke MW, Harder Y, Amon M, Martin I, Farhadi J, Ring A, Torio-Padron N, Schramm R, Rücker M, Junker D, et al: Angiogenesis in tissue engineering: Breathing life into constructed tissue substitutes. Tissue Eng 12: 2093-2104, 2006.

8. Feng T, Yu H, Xia Q, Ma Y, Yin H, Shen Y and Liu X: Cross-talk mechanism between endothelial cells and hepatocellular carcinoma cells via growth factors and integrin pathway promotes tumor angiogenesis and cell migration. Oncotarget 8: 69577-69593, 2017.

9. Addison-Smith B, McElwain DL and Maini PK: A simple mechanistic model of sprout spacing in tumour-associated angiogenesis. J Theor Biol 250: 1-15, 2008.

10. Chaplain MA, McDougall SR and Anderson AR: Mathematical modeling of tumor-induced angiogenesis. Annu Rev Biomed Eng 8: 233-257, 2006.

11. Livak KJ and Schmittgen TD: Analysis of relative gene expression data using real-time quantitative PCR and the 2(-Delta Delta C(T)) method. Methods 25: 402-408, 2001.

12. Lamalice L, Le Boeuf F and Huot J: Endothelial cell migration during angiogenesis. Circ Res 100: 782-794, 2007.

13. Gao D, Nolan DJ, Mellick AS, Bambino K, McDonnell K and Mittal V: Endothelial progenitor cells control the angiogenic switch in mouse lung metastasis. Science 319: 195-198, 2008.

14. Chiarugi V, Ruggiero M and Magnelli L: Molecular polarity in endothelial cells and tumor-induced angiogenesis. Oncol Res 12: $1-4,2000$.

15. Quail DF and Joyce JA: Microenvironmental regulation of tumor progression and metastasis. Nat Med 19: 1423-1437, 2013.

16. Tei K, Kawakami-Kimura N, Taguchi O, Kumamoto K, Higashiyama S, Taniguchi N, Toda K, Kawata R, Hisa Y and Kannagi R: Roles of cell adhesion molecules in tumor angiogenesis induced by cotransplantation of cancer and endothelial cells to nude rats. Cancer Res 62: 6289-6296, 2002.

17. Watnick RS: The role of the tumor microenvironment in regulating angiogenesis. Cold Spring Harb Perspect Med 2: a006676, 2012.

18. Samples J, Willis M and Klauber-DeMore N: Targeting angiogenesis and the tumor microenvironment. Surg Oncol Clin N Am 22: 629-639, 2013.

19. Chouaib S, Kieda C, Benlalam H, Noman MZ, Mami-Chouaib F and Rüegg C: Endothelial cells as key determinants of the tumor microenvironment: Interaction with tumor cells, extracellular matrix and immune killer cells. Crit Rev Immunol 30: 529-545, 2010.

20. Stroka KM, Vaitkus JA and Aranda-Espinoza H: Endothelial cells undergo morphological, biomechanical, and dynamic changes in response to tumor necrosis factor- $\alpha$. Eur Biophys J 41 : 939-947, 2012.

21. Guo J, Liu C, Zhou X, Xu X, Deng L, Li X and Guan F: Conditioned medium from malignant breast cancer cells induces an EMT-Like Phenotype and an Altered N-Glycan profile in Normal Epithelial MCF10A cells. Int J Mol Sci 18: pii: E1528, 2017.

22. Khodarev NN, Yu J, Labay E, Darga T, Brown CK, Mauceri HJ, Yassari R, Gupta N and Weichselbaum RR: Tumour-endothelium interactions in co-culture: Coordinated changes of gene expression profiles and phenotypic properties of endothelial cells. J Cell Sci 116: 1013-1022, 2003 
23. Bjerregaard B, Holck S, Christensen IJ and Larsson LI: Syncytin is involved in breast cancer-endothelial cell fusions. Cell Mol Life Sci 63: 1906-1911, 2006.

24. Dittmar T, Nagler C, Niggemann B and Zanker KS: The dark side of stem cells: Triggering cancer progression by cell fusion. Curr Mol Med 13: 735-750, 2013.

25. Kuhbier JW, Bucan V, Reimers K, Strauss S, Lazaridis A, Jahn S, Radtke C and Vogt PM: Observed changes in the morphology and phenotype of breast cancer cells in direct co-culture with adipose-derived stem cells. Plast Reconstr Surg 134: 414-423, 2014.

26. Zhang LN, Kong CF, Zhao D, Cong XL, Wang SS, Ma L and Huang YH: Fusion with mesenchymal stem cells differentially affects tumorigenic and metastatic abilities of lung cancer cells. J Cell Physiol 234: 3570-3582, 2019.

27. Mortensen K, Lichtenberg J, Thomsen PD and Larsson LI: Spontaneous fusion between cancer cells and endothelial cells. Cell Mol Life Sci 61: 2125-2131, 2004.

28. An R, Schmid R, Klausing A, Robering JW, Weber M, Bäuerle T, Detsch R, Boccaccini AR, Horch RE, Boos AM and Weigand A: Proangiogenic effects of tumor cells on endothelial progenitor cells vary with tumor type in an in vitro and in vivo rat model. Faseb J 32: 5587-5601, 2018

29. Ding Q, Xia Y, Ding S, Lu P, Sun L, Fan Y, Li X, Wang Y, Tian DA and Liu M: Potential role of CXCL9 induced by endothelial cells/CD133+ liver cancer cells co-culture system in tumor transendothelial migration. Genes Cancer 7: 254-259, 2016.

30. Lin SY, Yang J, Everett AD, Clevenger CV, Koneru M, Mishra PJ, Kamen B, Banerjee D and Glod J: The isolation of novel mesenchymal stromal cell chemotactic factors from the conditioned medium of tumor cells. Exp Cell Res 314: 3107-3117, 2008.

31. Novosel EC, Kleinhans C and Kluger PJ: Vascularization is the key challenge in tissue engineering. Adv Drug Deliv Rev 63: 300-311, 2011.

32. Cartland SP, Genner SW, Zahoor A and Kavurma MM: Comparative evaluation of TRAIL, FGF-2 and VEGF-A-induced angiogenesis in vitro and in vivo. Int J Mol Sci 17: pii: E2025, 2016.

33. Wei B, Han XY, Qi CL, Zhang S, Zheng ZH, Huang Y, Chen TF and Wei HB: Coaction of spheroid-derived stem-like cells and endothelial progenitor cells promotes development of colon cancer. PLoS One 7: e39069, 2012.

34. Maniotis AJ, Folberg R, Hess A, Seftor EA, Gardner LM, Pe'er J, Trent JM, Meltzer PS and Hendrix MJ: Vascular channel formation by human melanoma cells in vivo and in vitro: Vasculogenic mimicry. Am J Pathol 155: 739-752, 1999.

35. Yang Y, Jin G, Liu H, Liu K, Zhao J, Chen X, Wang D, Bai R, Li X and Jang Y: Metformin inhibits esophageal squamous cell carcinoma-induced angiogenesis by suppressing JAK/STAT3 signaling pathway. Oncotarget 8: 74673-74687, 2017.

36. Katkoori VR, Basson MD, Bond VC, Manne U and Bumpers HL: Nef-M1, a peptide antagonist of CXCR4, inhibits tumor angiogenesis and epithelialtomesenchymal transition in colon and breast cancers. Oncotarget 6: 27763-27777, 2015.

37. Gasparini G and Harris AL: Clinical importance of the determination of tumor angiogenesis in breast carcinoma: much more than a new prognostic tool. J Clin Oncol 13: 765-782, 1995
38. Xiong YQ, Sun HC, Zhang W, Zhu XD, Zhuang PY, Zhang JB, Wang L, Wu WZ, Qin LX and Tang ZY: Human hepatocellular carcinoma tumor-derived endothelial cells manifest increased angiogenesis capability and drug resistance compared with normal endothelial cells. Clin Cancer Res 15: 4838-4846, 2009.

39. Duncan GS, Andrew DP, Takimoto H, Kaufman SA, Yoshida H, Spellberg J, de la Pompa JL, Elia A, Wakeham A, Karan-Tamir B, et al: Genetic evidence for functional redundancy of platelet/endothelial cell adhesion molecule-1 (PECAM-1): CD31-deficient mice reveal PECAM-1-dependent and PECAM-1-independent functions. J Immunol 162: 3022-3030, 1999.

40. Yu Y, Huang X, Di Y, Qu L and Fan N: Effect of CXCL12/CXCR4 signaling on neuropathic pain after chronic compression of dorsal root ganglion. Sci Rep 7: 5707, 2017.

41. Okada H, Tsuzuki T, Shindoh H, Nishigaki A, Yasuda K and Kanzaki H: Regulation of decidualization and angiogenesis in the human endometrium: Mini review. J Obstet Gynaecol Res 40: 1180-1187, 2014.

42. Yang P, Chen N, Jia JH, Gao XJ, Li SH, Cai J and Wang Z: Tie-1: A potential target for anti-angiogenesis therapy. J Huazhong Univ Sci Technolog Med Sci 35: 615-622, 2015.

43. Zanetta L, Marcus SG, Vasile J, Dobryansky M, Cohen H, Eng K, Shamamian P and Mignatti P: Expression of Von Willebrand factor, an endothelial cell marker, is up-regulated by angiogenesis factors: A potential method for objective assessment of tumor angiogenesis. Int J Cancer 85: 281-288, 2000.

44. Liang T, Zhu L, Gao W, Gong M, Ren J, Yao H, Wang K and Shi D: Coculture of endothelial progenitor cells and mesenchymal stem cells enhanced their proliferation and angiogenesis through PDGF and Notch signaling. FEBS Open Bio 7: 1722-1736, 2017.

45. West CC, Brown NJ, Mangham DC, Grimer RJ and Reed MW: Microvessel density does not predict outcome in high grade soft tissue sarcoma. Eur J Surg Oncol 31: 1198-1205, 2005.

46. Weidner N, Semple JP, Welch WR and Folkman J: Tumor angiogenesis and metastasis-correlation in invasive breast carcinoma N Engl J Med 324: 1-8, 1991.

47. Tomlinson J, Barsky SH, Nelson S, Singer S, Pezeshki B, Lee MC, Eilber F and Nguyen M: Different patterns of angiogenesis in sarcomas and carcinomas. Clin Cancer Res 5: 3516-3522, 1999.

48. Rocchi L, Caraffi S, Perris R and Mangieri D: The angiogenic asset of soft tissue sarcomas: A new tool to discover new therapeutic targets. Biosci Rep 34: e00147, 2014.

49. Kami Reddy KR, Dasari C, Vandavasi S, Natani S, Supriya B, Jadav SS, Sai Ram N, Kumar JM and Ummanni R: Novel cellularly active inhibitor regresses DDAH1 induced prostate tumor growth by restraining tumor angiogenesis through targeting DDAH1/ADMA/NOS pathway. ACS Comb Sci, 2019 (Epub ahead of print).

50. Lacal PM and Graziani G: Therapeutic implication of vascular endothelial growth factor receptor-1 (VEGFR-1) targeting in cancer cells and tumor microenvironment by competitive and non-competitive inhibitors. Pharmacol Res 136: 97-107, 2018. 